\title{
Use of ATR-FTIR Spectroscopy and Chemometrics for the Variation of Active Components in Different Harvesting Periods of Lonicera japonica
}

\author{
Yun-Chu Zhang $\mathbb{D}^{1,2}$ Jing Deng, ${ }^{1}$ Xiu-Lian Lin, ${ }^{1}$ Ya-Mei Li, ${ }^{1}$ Han-Xuan Sheng, \\ Bo-Hou Xia $\mathbb{D}^{1,3}$ and Li-Mei Lin $\mathbb{D}^{1}$ \\ ${ }^{1}$ Key Laboratory for Quality Evaluation of Bulk Herbs of Hunan Province, Hunan University of Chinese Medicine, \\ Changsha 410208, China \\ ${ }^{2}$ State Key Laboratory of Natural Medicines (SKLNM) and Jiangsu Key Laboratory of Bioactive Natural Product Research, \\ Department of Medicinal Chemistry, China Pharmaceutical University, Nanjing 210009, China \\ ${ }^{3}$ Hunan Key Laboratory of Druggability and Preparation Modification for Traditional Chinese Medicine, \\ Changsha 410208, China
}

Correspondence should be addressed to Bo-Hou Xia; xiabohou@163.com and Li-Mei Lin; lizasmile@163.com

Received 30 April 2020; Revised 26 July 2021; Accepted 13 September 2021; Published 7 March 2022

Academic Editor: Valentina Venuti

Copyright (c) 2022 Yun-Chu Zhang et al. This is an open access article distributed under the Creative Commons Attribution License, which permits unrestricted use, distribution, and reproduction in any medium, provided the original work is properly cited.

\begin{abstract}
Lonicera japonica Thunb is a commonly used Chinese herbal medicine, which belongs to the family Caprifoliaceae. The active components varied greatly during bud development. Research on the variation of the main active components is significant for the timely harvesting and quality control of Lonicera japonica. In this study, the attenuated total reflection Fourier transform infrared spectroscopy (ATR-FTIR) combined with the chemometric method was performed to investigate the variability of different harvesting periods of Lonicera japonica. The preliminary characterization from ATR-FTIR fingerprints showed various characteristic absorption peaks of the main active components from the different harvesting times, such as flavonoids, organic acids, iridoids, and volatile oils. Additionally, principal component analysis (PCA) scatter plots showed that there was a clear clustering trend in the samples of the same harvesting period, and the samples of the different harvesting periods could be well distinguished. Finally, further analysis by the orthogonal partial least-squares discriminant analysis (OPLS-DA) showed that there were regular changes in flavonoids, phenolic acids, iridoids, and volatile oils in different harvesting periods. Therefore, ATR-FTIR, as a novel and convenient analytical method, could be applied to evaluate the quality of Lonicera japonica.
\end{abstract}

\section{Introduction}

Traditional Chinese medicine has a long history in China. It is a summary of the long-term life experience of the Chinese people. With the development of medical undertakings, Chinese medicines play an increasingly important role in disease treatments, beauty care, regimen, and immunity enhancement. The composition of Chinese medicines is complex and susceptible to the origin, climate, and harvesting periods, making it challenging to control quality. The quality of Chinese medicines is determined mainly by the content of active components, which is closely related to the harvesting period [1-4]. Therefore, the harvesting period is an essential factor affecting the quality of Chinese medicines.

Lonicera japonica is the dried flower buds, the initial opening flower, of Lonicera japonica Thunb. It has the efficacy of heat clearing, detoxifying, and evacuating wind heat [5]. The chemical composition of Lonicera japonica is complicated. It contains bioactive components, such as chlorogenic acid and its analogs, flavonoids, iridoid glycosides, and triterpenoid saponins [6]. At present, Lonicera japonica has been widely used in the medicine and food 
industry. However, the quality of Lonicera japonica on the market is mixed due to its concentrated flowering period, short harvesting time, and the effect of varieties, processing methods, and transportation conditions. Moreover, flower buds of different harvesting periods are easily mixed and distinctly different in the content of the main bioactive components, making it difficult to exert the corresponding clinical effect when used as drugs. Therefore, it is of great significance to study the variation of active components of Lonicera japonica in growth stages for its quality control.

Currently, in-depth research on the dissimilarity in different harvesting periods of Lonicera japonica is limited. The research on Lonicera japonica mainly focuses on the relevant aspects of the content changes in active components. Jiang et al. [7] studied the anti-inflammatory activity from different flowering phases of Lonicera japonica by high-performance liquid chromatography (HPLC). They found that the anti-inflammatory effects of Lonicera japonica gradually decrease as the flowering progressed. However, the preprocessing of this method is relatively complicated, and it acquires plenty of time and energy. Fu et al. [8] applied the HPLC to study the content changes in the primary antioxidants at different developmental stages of Lonicera japonica. The study revealed that chlorogenic acid and its derivatives have the strongest antioxidant capacity. Additionally, the highest content of chlorogenic acid was found before flowering. This helps to choose the harvesting period in which Lonicera japonica had the strongest antioxidant capacity. However, the shortcoming is that the flowering period is relatively short and not clear enough. Therefore, there is a need to develop a method and technique that is handy, rapid, economical, strong fingerprinting, and capable of fully characterizing the chemical composition of Lonicera japonica.

In addition to the above research methods, the common methods for studying the quality difference in Chinese medicinal materials in recent years include ultraviolet-visible spectrophotometry (UV-Vis), Fourier transform infrared spectroscopy (FTIR), liquid chromatography-mass spectrometer (LC-MS), gas chromatography-mass spectrometer (GC-MS), and nuclear magnetic resonance spectroscopy (NMR). Among them, UV-Vis has low sensitivity to compounds with weak UV absorption. The application scope of GC-MS is relatively limited, and it is often used to determine volatile compounds. The sample pretreatment and detection processes of LC-MS and NMR are complicated, and thus, they can be time-consuming and costly. However, FTIR technology is an effective, economical, fast, and strong fingerprinting detection method. It can be used nondestructively and rapidly to obtain biochemical fingerprints that provide information about molecular structure and composition [9]. Moreover, in recent years, ATR-FTIR technology has been developed based on FTIR technology, which can be equipped with ATR accessories for crystal materials, such as zinc selenide, germanium, and diamond. Only a small number of samples are needed, so sampling is quick and straightforward, with no pretreatment required. This technology is used for qualitative and quantitative analysis $[10,11]$. It is a "green analysis method," which has been extensively used in the research field of medicine and food chemical composition.

Therefore, in this study, the ATR-FTIR method was performed to establish the chemical information fingerprint of Lonicera japonica in five different harvesting periods. The sample data from these five periods were further analyzed and compared by applying chemometric methods, such as PCA and OPLS-DA. Moreover, to ensure the sustainable utilization of medicinal resources with high-quality and high-yield, the variation characteristics of the five periods were also discussed.

\section{Materials and Methods}

2.1. Instruments. The Fourier transform infrared spectrometer is equipped with ATR accessory (Nicolet iS5, Thermo Scientific, USA), 101 types of electrothermal blowing dry box (Beijing Yongguangming Medical Instrument Factory), DJ-10A pulverizer (Shanghai Longtuo Instrument Equipment Co., Ltd.), and 100 mesh standard sieve tray (Shangyu City, Zhejiang Province Yarn Screening Factory).

2.2. Plant Materials and Sample Collection. Lonicera japonica flower buds were collected from the medicine plantation of Hunan University of Chinese Medicine in April in Changsha, Hunan, China $\left(112^{\circ} 54^{\prime} \mathrm{E} ; 28^{\circ} 08^{\prime} \mathrm{N}\right)$. The well-developed Lonicera japonica samples were harvested at different time points. According to the color of the alabastrum, the flower bud differentiation process was divided into five periods including young alabastrum, green alabastrum, white alabastrum, silvery, and golden flower periods, named ya, ga, wa, sf, and gf, respectively (sample characteristics of each period are shown in Figure 1). The samples of three different positions were mixed in each period as one sample, and five samples were collected in each period.

2.3. Sample Preparation. The samples were rinsed with distilled water, were dried in the shade, and then placed in an oven. After drying at a constant temperature of $60^{\circ} \mathrm{C}$ until achieving constant weight, the samples were crushed and screened through a mesh size of 100 . All samples were stored in a dryer until the ATR-FTIR analysis.

2.4. ATR-FTIR Spectra Collection. To deduct the interference of the absorption of dihydrogen oxide and carbon dioxide, the ATR-FTIR spectra of the air, accumulating 36 scans per spectra, were performed as background with $8 \mathrm{~cm}^{-1}$ resolution. When concerning sample test, a small amount of Lonicera japonica samples were taken on the dry and clean zinc selenide crystal material for spectral scanning in the range of $4000-500 \mathrm{~cm}^{-1}$ under the room temperature. After collecting every one sample, the ATR crystal was washed with a cotton ball dipped in alcohol until it was non-contaminated, and then, the next sample was collected. 


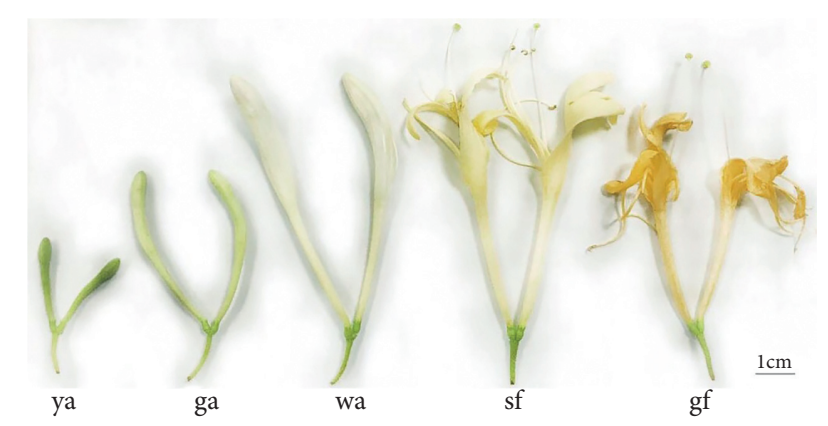

FIgURE 1: Sample characteristics of Lonicera japonica in five periods.

2.5. Data Processing. Firstly, the ATR-FTIR fingerprint of Lonicera japonica was processed by Origin 2017 software, and then, SIMCA-P ${ }^{+} 15.0$ software was adopted to conduct the first derivative (FD), second derivative (SD), standard normal variate $(\mathrm{SNV})$, multiplicative scatter correction (MSC), Savitzky-Golay smoothing (S-G), exponentially weighted moving average (EWMA), and row center (RC) preprocessing on the spectral data. Each preprocessing method was processed by six scaling methods, namely unit variance (UV), unit variance none (UVN), Pareto (Par), Pareto none (ParN), centering (Ctr), and freeze (their definitions are shown in Table $1[12,13])$. Then, the classification and discrimination models are constructed by combining PCA, OPLS-DA, and other chemometric methods. These preprocessing methods could improve the stability and accuracy of the model [14]. The optimal preprocessing method was $\mathrm{SD}$. The $R^{2}$ and $Q^{2}$ values of the models range between 0 and 1 , with higher values (greater than 0.5) indicating higher model fit and predictability [15]. Permutation tests (100 times) and S-line plots were used in the OPLS-DA model for model evaluation and screening of differential components. The $R^{2} Y$ (close to 1 ) and $Q^{2} Y$ intercepts (less than zero) in the permutation plot were applied to evaluate whether the model was overfitted [16]. S-line plots were used to identify statistically significant and potentially biochemically significant metabolites, based on both contributions to the model (greater than 0.8 ) and their reliability [17].

\section{Results and Discussion}

3.1. ATR-FTIR Fingerprint Analysis. Infrared fingerprints have a large amount of information and strong specificity, which can provide the information of main chemical constituents in medicinal materials. Different chemical components have their own infrared characteristic peaks [18]. The difference in absorption value and peak intensity can reflect the dissimilarity of the main chemical components of Lonicera japonica in different periods. The ATR-FTIR fingerprint of different harvesting periods and the composition and group information of different bands are shown in Figure 2 and Table 2, respectively. The results showed that there was a sharp absorption peak appeared near $1105 \mathrm{~cm}^{-1}$ in the ya stage, which could be distinguished from other periods, corresponding to the overlapped absorption peak of
-OH bending vibration and $\mathrm{C}-\mathrm{O}$ stretching vibration of flavonoids or organic acids. The ga stage has obvious absorption near $1255 \mathrm{~cm}^{-1}$ and $1378 \mathrm{~cm}^{-1}$, corresponding to the characteristic absorption of $\mathrm{C}-\mathrm{O}$ of organic acid. There was a strong infrared absorption peak near $1055 \mathrm{~cm}^{-1}$ at the wa stage, corresponding to the overlapped absorption peak of - $\mathrm{OH}$ bending vibration and $\mathrm{C}-\mathrm{O}$ stretching vibration of phenolic acid or flavonoids. This indicated that the content of phenolic acids and flavonoids is abundant in this period. The sf stage has obvious absorption near $1656 \mathrm{~cm}^{-1}$, corresponding to the absorption peak of $\mathrm{C}=\mathrm{C}$ stretching vibration of iridoids. At the gf stage, a sharp absorption peak near 2956 appeared, which could be distinguished from other periods, corresponding to the absorption peak of $-\mathrm{CH}_{3}$ stretching vibration of volatile oils. Additionally, there was an obvious absorption near $1634 \mathrm{~cm}^{-1}$, corresponding to the absorption peak of aromatic ring skeleton vibration of flavonoids or phenolic acid. It can be seen from the above analysis that the dissimilarity of these principal components might be an important reason for the variability of Lonicera japonica in different harvesting periods. However, due to the complexity of infrared fingerprints, it is difficult to distinguish the subtle differences in many bands by manual observation and comparison only; hence chemometric methods are desired to establish classification and discriminant models for further analysis.

3.2. Overall Variance Analysis by Principal Component Analysis. SIMCA is a supervised classification technique that uses samples with known origin (training samples) to derive a classification rule, which allows classifying new samples (test samples) with unknown origin in one of the classes, based on the values of the features of the new samples [34]. PCA is a mathematical algorithm that reduces the dimensionality of the data and can intuitively reflect the spatial distribution of the sample in the mathematical model while retaining most of the variation in the data set, which helps to understand the overall situation of the data and improve the accuracy of the model [35]. The results of the six scaling methods are shown in Figure 3. UV was chosen as the optimized scaling method for PCA model, and the results are shown in Figure 4 (three-dimensional). The model fitting parameter $R^{2} X=0.784$, and the model prediction parameter $Q^{2}=0.511$, both of which are greater than 0.5 , indicating that the model has a good fitting degree and strong predictive ability. There was a significant clustering trend of the Lonicera japonica samples in the same harvesting period. The samples in the ya stage and the gf stage could be significantly distinguished from those in other stages, indicating that the chemical components in these two periods are distinct. The spatial distribution of some samples in the ga stage, wa stage, and sf stage was relatively close, indicating that the variation of chemical components in these three periods was comparatively slight.

3.3. Individual Variance Analysis by Orthogonal Partial LeastSquares Discriminant Analysis. To better distinguish the differences between groups and to specify the dissimilarity 
TABLE 1: Definition of six scaling methods.

\begin{tabular}{|c|c|}
\hline $\begin{array}{l}\text { Scaling } \\
\text { method }\end{array}$ & Definition \\
\hline UV & $\begin{array}{c}\text { The variable } j \text { is centered and scaled to "unit variance," which means that the base weight is computed as the reciprocal of } \\
\text { the standard deviation of variable } j \text { computed around the mean (sdj) }\end{array}$ \\
\hline UVN & Similar to UV, the variable is not centered, which means that the standard deviation is computed around zero \\
\hline Par & $\begin{array}{c}\text { Between no scaling and UV scaling. The variable } j \text { is centered and scaled to Pareto variance, which means that the base } \\
\text { weight is computed as } 1 / \text { sqrt (sdj) }\end{array}$ \\
\hline ParN & Similar to par, however, the variable is not centered \\
\hline Ctr & A column-wise centering to transform values varies around zero \\
\hline Freeze & $\begin{array}{c}\text { The scaling weight of the variable is frozen and will not be recomputed as observations in the work set change or the } \\
\text { variable metric is modified }\end{array}$ \\
\hline
\end{tabular}

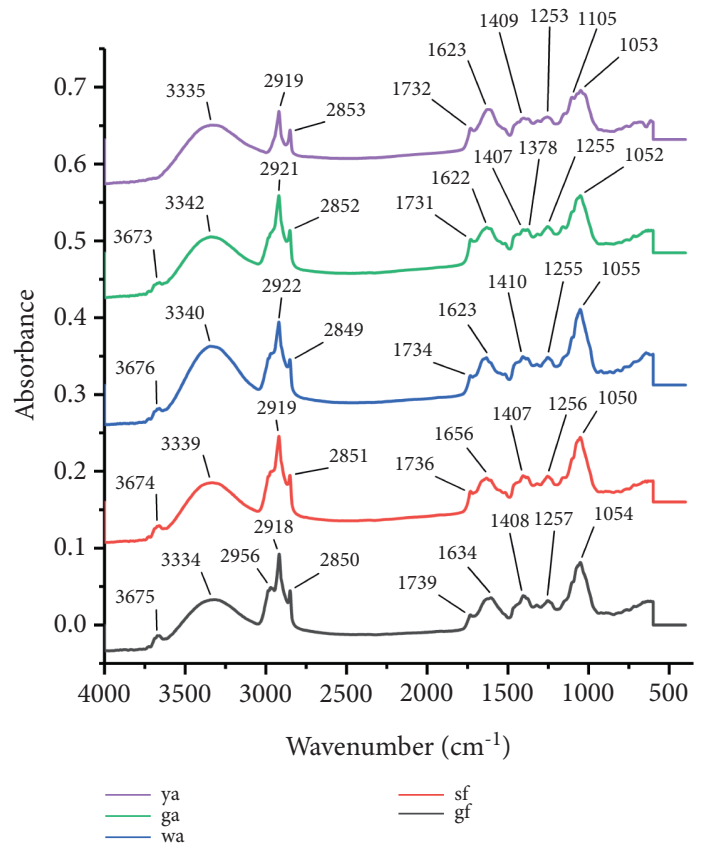

FIGURE 2: ATR-FTIR fingerprint of Lonicera japonica in different harvesting periods.

TABLE 2: Infrared spectrum band assignments.

\begin{tabular}{|c|c|c|c|}
\hline Wavenumber $\left(\mathrm{cm}^{-1}\right)$ & Vibration & Suggested biomolecular assignment & Reference \\
\hline $4000-3500$ & O-H stretching & $\mathrm{H}_{2} \mathrm{O}$ & [14] \\
\hline $3800-2600$ & -OH stretching & Water molecules & {$[19]$} \\
\hline 3615 & $v_{\mathrm{s}}(\mathrm{OH})$ free & Water molecules & [19] \\
\hline 3490 & $v_{\mathrm{as}}(\mathrm{OH}), \mathrm{HB}$ & Water molecules & {$[19]$} \\
\hline 3420,3400 & $v_{\mathrm{s}}(\mathrm{OH}), \mathrm{HB}$ & Water molecules & [19] \\
\hline 3400 & $\mathrm{O}-\mathrm{H}$ bond vibration & Sugar compound & {$[20]$} \\
\hline 3400 & Free N-H stretching & Amide & {$[19]$} \\
\hline 3392 & O-H stretching & & {$[21]$} \\
\hline 3307 & -OH deformation mode & & {$[22]$} \\
\hline$\sim 3300$ & $v(\mathrm{NH}), \mathrm{HB}$ & Amide A, proteins & [19] \\
\hline $3286-3284$ & $\mathrm{~N}-\mathrm{H}$ stretching & Amide $\mathrm{A}$ of proteins & {$[23]$} \\
\hline $3286-3284$ & $\mathrm{O}-\mathrm{H}$ stretching & Polysaccharides & {$[23]$} \\
\hline 3286 & $\mathrm{~N}-\mathrm{H}$ stretching & Amide & {$[24]$} \\
\hline 3280 & $v_{\mathrm{s}}(\mathrm{OH}), \mathrm{HB}$ & Water molecules & [19] \\
\hline 3280 & $\mathrm{H}-\mathrm{O}-\mathrm{H}$ stretching & & {$[25]$} \\
\hline$\sim 3100$ & $v(\mathrm{NH}), \mathrm{HB}$ & Amide $\mathrm{B}$, proteins & [19] \\
\hline 3077 & $\nu \mathrm{CH}$ & Alkane/alkene & [24] \\
\hline
\end{tabular}


TABle 2: Continued.

\begin{tabular}{|c|c|c|c|}
\hline Wavenumber $\left(\mathrm{cm}^{-1}\right)$ & Vibration & Suggested biomolecular assignment & Reference \\
\hline $3030-2800$ & & Lipids & [23] \\
\hline $3020-3010$ & $v(=\mathrm{CH})$ & Unsaturated fatty acids, cholesterol esters & [19] \\
\hline 3008 & Olefinic $\mathrm{HC}=\mathrm{CH}$ & Unsaturated lipids & [23] \\
\hline $3000-2800$ & $-\mathrm{CH}_{3}$ and $-\mathrm{CH}_{2}$ groups & Phospholipids and fatty acids & [19] \\
\hline $2960-2955$ & $v_{\text {as }}\left(\mathrm{CH}_{3}\right)$ & $\begin{array}{c}\text { Protein side chains, phospholipids, } \\
\text { ceramides, fatty acids }\end{array}$ & {$[19]$} \\
\hline 2960 & $\mathrm{CH}_{3}$ - stretching (asym) & Alkane/alkene & {$[24]$} \\
\hline 2957 & Asymmetric $\mathrm{CH}_{3}$ stretching & & {$[25]$} \\
\hline 2956 & $\mathrm{CH}_{3}$ antisymmetric stretching & Lipids, protein side chains & {$[23]$} \\
\hline 2924-2915 & $v_{\text {as }}\left(\mathrm{CH}_{2}\right)$ & $\begin{array}{c}\text { Mainly lipids: phospholipids, ceramides, and } \\
\text { fatty acids }\end{array}$ & [19] \\
\hline 2923,2853 & $\mathrm{CH}_{2}-$ stretching & & [21] \\
\hline 2923 & $\mathrm{CH}_{2}$ antisymmetric stretching & Lipids (mainly) & {$[23]$} \\
\hline 2920 & Asymmetric $\mathrm{CH}_{2}$ stretching & & {$[25]$} \\
\hline 2900 & C-H bonds & Sugar compounds & [20] \\
\hline $2875-2872$ & $v_{\mathrm{s}}\left(\mathrm{CH}_{3}\right)$ & $\begin{array}{c}\text { Protein side chains, phospholipids, } \\
\text { ceramides, fatty acids }\end{array}$ & {$[19]$} \\
\hline 2872 & $\mathrm{CH}_{3}$ - stretching (sym) & Alkane/alkene & {$[24]$} \\
\hline 2872 & $\mathrm{CH}_{3}$ symmetric stretching & $\begin{array}{c}\text { Proteins (mainly), lipids, carbohydrates, } \\
\text { nucleic acids }\end{array}$ & [23] \\
\hline $2855-2847$ & $v_{\mathrm{s}}\left(\mathrm{CH}_{2}\right)$ & $\begin{array}{l}\text { Mainly lipids: phospholipids, ceramides, fatty } \\
\text { acids }\end{array}$ & {$[19]$} \\
\hline 2854 & $\mathrm{CH}_{2}$ symmetric stretching & Lipids (mainly) & {$[26]$} \\
\hline 2844 & $\mathrm{CH}_{2}-$ stretching & & {$[22]$} \\
\hline $2700-2330$ & $\begin{array}{c}\mathrm{NH}^{+} \text {stretching and overtones or } \\
\text { combination bands in Fermi resonance }\end{array}$ & Tertiary amine hydrochloride salts & [9] \\
\hline $2500-2000$ & & Unsaturated hydrocarbons & [27] \\
\hline $2442-2208$ & $\mathrm{O}-\mathrm{C}-\mathrm{O}$ stretching & $\mathrm{CO}_{2}$ & {$[14]$} \\
\hline $2400-2250$ & & $\mathrm{CO}_{2}$ & {$[26]$} \\
\hline 2360,2340 & & $\mathrm{CO}_{2}$ & {$[26]$} \\
\hline 1900 & The 2nd overtone of the $\mathrm{CO}$ bond & Caffeoylquinic acids & {$[28]$} \\
\hline $1800-1650$ & & Chlorogenic acid & [29] \\
\hline $1800-900$ & Fingerprint region & All molecules & {$[23]$} \\
\hline 1742 & Carbonyl $\mathrm{C}=\mathrm{O}$ stretching & Cholesterol esters & {$[23]$} \\
\hline 1740 & & Triglycerides & {$[30]$} \\
\hline $1740-1720$ & $\nu(\mathrm{C}=\mathrm{O})$ & Phospholipids, esters, glycerides & {$[19]$} \\
\hline $\begin{array}{l}1734,1627,1522,1440,1410,1367 \\
1315,1255\end{array}$ & & Chlorogenic acid, flavonoids & {$[22]$} \\
\hline 1734 & $\mathrm{C}=\mathrm{O}$ stretching & Polyphenol & {$[22]$} \\
\hline 1720 & The asymmetric overtone of the $\mathrm{C}-\mathrm{H}$ bond & Caffeoylquinic acids & {$[28]$} \\
\hline $1700-1400$ & & Fatty acids, lipids, proteins & {$[30]$} \\
\hline $1690-1610$ & $\nu(\mathrm{C}=\mathrm{O})$ & Amide I ( $70-80 \% \mathrm{C}=\mathrm{O}$ stretch) & {$[19]$} \\
\hline $\begin{array}{l}1682,1639,1471,1284,1181,1111 \\
1032,982,950,822,789\end{array}$ & & Organic acids, flavonoids & {$[22]$} \\
\hline 1682 & $\mathrm{C}=\mathrm{O}$ stretching & Chlorogenic acid & {$[22]$} \\
\hline 1650 & $\mathrm{C}=\mathrm{O}$ stretching & Amide I (proteins, lipids, and carbohydrates) & {$[24]$} \\
\hline 1650 & The first $\mathrm{C}-\mathrm{H}$ overtone & & {$[31]$} \\
\hline 1644 & & Triterpenoid saponin & [32] \\
\hline 1641 & $\mathrm{C}=\mathrm{O}$ stretching $\beta$-sheet structure & Amide I (protein) & {$[23]$} \\
\hline 1636 & $\mathrm{C}=\mathrm{C}$ vibrations (aromatic ring skeletal) & & {$[22]$} \\
\hline 1635 & & The crystalline water of sugar compounds & {$[20]$} \\
\hline 1627,1522 & $\mathrm{C}=\mathrm{C}$ vibrations (aromatic ring skeletal) & & {$[22]$} \\
\hline $1600-1450$ & & Secologanic acid, chlorogenic acid, galuteolin & {$[33]$} \\
\hline 1590 & & Amino acids & {$[30]$} \\
\hline $1560-1500$ & $\delta(\mathrm{NH}), \nu(\mathrm{CN})$ & $\begin{array}{c}\text { Amide II }(\sim 40-60 \% \mathrm{~N}-\mathrm{H} \text { in-plane bend, } \\
\sim 20-40 \% \mathrm{C}-\mathrm{N} \text { stretch })\end{array}$ & {$[19]$} \\
\hline $1545,1455,1450,1410,880,875$ & & Carbonate & [26] \\
\hline 1538 & $\mathrm{~N}-\mathrm{H}$ bend, C-N stretch a helical structure & Amide II (protein) & {$[23]$} \\
\hline 1516 & & Tyrosine & {$[30]$} \\
\hline 1491 & $\mathrm{C}=\mathrm{C}$ aromatic ring stretching vibrations & & [9] \\
\hline
\end{tabular}


TABle 2: Continued.

\begin{tabular}{|c|c|c|c|}
\hline Wavenumber $\left(\mathrm{cm}^{-1}\right)$ & Vibration & Suggested biomolecular assignment & Reference \\
\hline $1473-1468$ & $\delta\left(\mathrm{CH}_{2}\right), \delta \mathrm{as}\left(\mathrm{CH}_{3}\right)$ & Proteins, lipids & [19] \\
\hline 1462 & $\delta\left(\mathrm{CH}_{2}\right), \delta \mathrm{as}\left(\mathrm{CH}_{3}\right)$ & Proteins, lipids & {$[19]$} \\
\hline $1454-1451$ & $\mathrm{CH}_{2}$ bending & Lipids & {$[23]$} \\
\hline 1454 & $\delta\left(\mathrm{CH}_{2}\right), \delta \operatorname{as}\left(\mathrm{CH}_{3}\right)$ & Proteins, lipids & [19] \\
\hline 1453 & $\mathrm{CH}_{2}$ scissoring & & {$[25]$} \\
\hline $1440,1410,1376$ & $\mathrm{OH}$ vibrational modes & Organic acid & {$[22]$} \\
\hline 1428,1407 & $\mathrm{NCH}_{3}$ bending & & {$[9]$} \\
\hline $1420-1300$ & The second overtone of the carbonyl group & Secologanic acid, chlorogenic acid, galuteolin & {$[33]$} \\
\hline 1413 & $\begin{array}{c}\mathrm{C}-\mathrm{H} \text { deformation vibration }\left(\mathrm{CH}_{3} \text { and }\right. \\
\left.-\mathrm{CH}_{2} \text { - groups }\right)\end{array}$ & & {$[28]$} \\
\hline 1412 & $\mathrm{O}-\mathrm{C}=\mathrm{O}$ symmetric stretching & Glycine & {$[25]$} \\
\hline 1400 & $v(\mathrm{C}=\mathrm{O})+\delta \mathrm{s}\left(\mathrm{CH}_{3}\right)$ & COO-: proteins, lipids, fatty acids & [19] \\
\hline 1398 & $\mathrm{CH}_{3}$ bending & Proteins & {$[14]$} \\
\hline 1398 & COO- stretching (sym) & Fatty acids, amino acids & {$[14]$} \\
\hline 1397 & COO- symmetric stretching & Fatty acids & [23] \\
\hline 1394 & $\mathrm{C}=\mathrm{O}$ stretch of $\mathrm{COO}-$ & & [25] \\
\hline 1393,1358 & $\begin{array}{c}\nu \mathrm{CO} / \nu \mathrm{COO}-, \delta \mathrm{CHx}(x=1,2,3), \delta \mathrm{NH} \\
\text { vibrational modes }\end{array}$ & Proteins and lipids & {$[24]$} \\
\hline 1350 & $\begin{array}{l}\text { The second overtone of stretching } \mathrm{O}-\mathrm{H} \\
\text { and C-H bonds }\end{array}$ & & {$[31]$} \\
\hline 1343 & $\delta\left(\mathrm{CH}_{2}\right)$ & $\mathrm{C}-\mathrm{H}$ wagging & {$[19]$} \\
\hline 1333 & $\mathrm{C}-\mathrm{H}_{2}$ wagging & Glycine & {$[25]$} \\
\hline 1315,1250 & $\mathrm{C}-\mathrm{O}$ stretching & & {$[22]$} \\
\hline 1243,1240 & $\nu(\mathrm{CN}), \delta(\mathrm{NH})+\nu_{\mathrm{as}}\left(\mathrm{PO}_{2}^{-}\right)$ & $\begin{array}{l}\text { Amide III ( } \sim 40 \% \mathrm{C}-\mathrm{N} \text { stretch, } 30 \% \mathrm{~N}-\mathrm{H} \text { in- } \\
\text { plane bend, } 20 \% \text { methyl-C stretch) }\end{array}$ & [19] \\
\hline 1242 & Asymmetric $\mathrm{PO}_{2}^{-}$stretch & & {$[25]$} \\
\hline 1241 & $v_{\mathrm{as}}\left(\mathrm{PO}_{2}^{-}\right)^{2}$ & Nucleic acids, phospholipids & {$[30]$} \\
\hline 1234 & $\mathrm{PO}_{2}^{-}$antisymmetric stretching & Nucleic acids (mainly), phospholipids & {$[23]$} \\
\hline $1200-1000$ & C-O stretching & Polysaccharides, glycosides & {$[21]$} \\
\hline $1200-1000$ & & Nucleic acids, hydrocarbons, phosphates & {$[24]$} \\
\hline $1200-900$ & $\nu(\mathrm{CC}), \delta(\mathrm{COH})$ & Carbohydrates & [19] \\
\hline $1190-976,962,660-520,472$ & & Phosphate ions & [26] \\
\hline 1171 & Ester C-O asymmetric stretch & & {$[25]$} \\
\hline $1170-1100$ & The second overtone of $\mathrm{C}-\mathrm{H}\left(-\mathrm{CH}_{2}\right)$ & Secologanic acid, chlorogenic acid, galuteolin & [33] \\
\hline 1167 & $\mathrm{C}-\mathrm{H}$ stretching $\left(\mathrm{CH}_{3}\right.$ and $-\mathrm{CH}_{2}-$ groups $)$ & & {$[28]$} \\
\hline 1166 & $\mathrm{CO}-\mathrm{O}-\mathrm{C}$ antisymmetric stretching & $\begin{array}{c}\text { Ester bonds in cholesteryl esters, ribose ring } \\
\text { formations: RNA }\end{array}$ & [23] \\
\hline 1155 & C-O stretching & Oligosaccharides, triacylglycerols & [14] \\
\hline $1152,1080,1022$ & $\delta(\mathrm{CHO}), v(\mathrm{C}-\mathrm{O})$ & Glycogen, glucose & {$[24]$} \\
\hline $1150-850$ & & Phosphate group & {$[26]$} \\
\hline 1150,1020 & -OH deformation modes & & {$[22]$} \\
\hline 1141,1079 & C-O glycosidic bonds & & {$[20]$} \\
\hline 1124 & $v(\mathrm{C}-\mathrm{O})$ & RNA & {$[30]$} \\
\hline 1120 & C-O bonds & Ribose & {$[30]$} \\
\hline 1118 & $v(\mathrm{C}-\mathrm{O})$ & RNA, carbohydrates & {$[30]$} \\
\hline 1117 & $\mathrm{~N}-\mathrm{H}_{3}$ rocking & Glycine & {$[25]$} \\
\hline 1091 & p-Substituted aromatic vibrations & & [9] \\
\hline $1090-1075$ & $v_{\mathrm{s}}\left(\mathrm{PO}_{2}^{-}\right)$ & Phospholipids & [19] \\
\hline 1080 & C-O stretch & & {$[25]$} \\
\hline 1074 & $\mathrm{PO}_{2}^{-}$symmetric stretching & $\begin{array}{l}\text { Nucleic acids, phospholipids, glycogen, } \\
\text { polysaccharides, glycolipids }\end{array}$ & [23] \\
\hline 1051 & $\mathrm{C}-\mathrm{O}$ stretching & Starch & {$[14]$} \\
\hline 1039 & $\mathrm{C}-\mathrm{N}$ stretching & Glycine & {$[25]$} \\
\hline 1034 & & Glycolytic components and nucleic acids & {$[24]$} \\
\hline $1010(1225-950)$ & Aromatic $\mathrm{C}-\mathrm{H}$ in-plane bending & & [9] \\
\hline 996 & & Nucleotides & [19] \\
\hline 971 & $\mathrm{C}-\mathrm{N}^{+}-\mathrm{C}$ stretching & RNA & {$[23]$} \\
\hline $950-400$ & & $\mathrm{H}_{2} \mathrm{O}$ & {$[24]$} \\
\hline 919 & Ribose ring vibrations & RNA/DNA & [23] \\
\hline $914-600$ & $\mathrm{O}-\mathrm{C}-\mathrm{O}$ bending & $\mathrm{CO}_{2}$ & {$[14]^{1}$} \\
\hline
\end{tabular}


TABle 2: Continued.

\begin{tabular}{lccc}
\hline Wavenumber $\left(\mathrm{cm}^{-1}\right)$ & Vibration & Suggested biomolecular assignment & Reference \\
\hline 914 & $\mathrm{CH}_{2}$ rocking & Glycine & {$[25]$} \\
894 & The $\beta$-configuration and $\alpha$-configuration & C-H deformation in proteins & {$[20]$} \\
877,744 & & & {$[19]$} \\
833,822 & Aromatic C-H out-of-plane bending & D-Glucopyranosyl ring & {$[20]$} \\
771 & C-O-C symmetry vibration & Lipids & {$[19]$} \\
$730-718$ & $\rho\left(\mathrm{CH}_{2}\right)$ & & \\
\hline
\end{tabular}

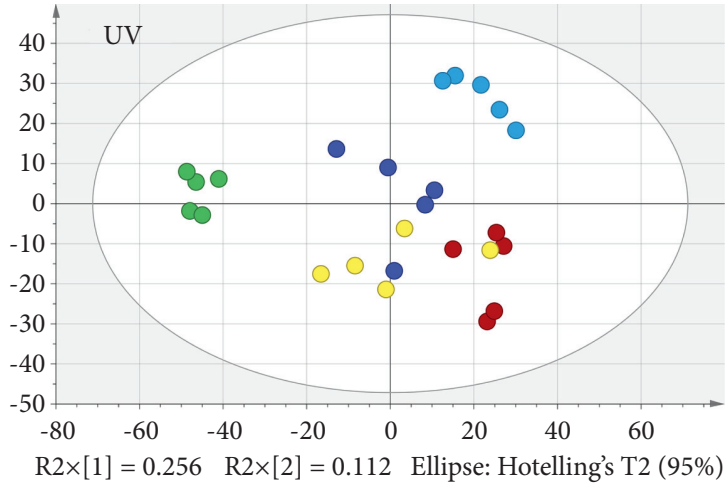

ya
ga
wa

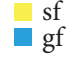

(a)

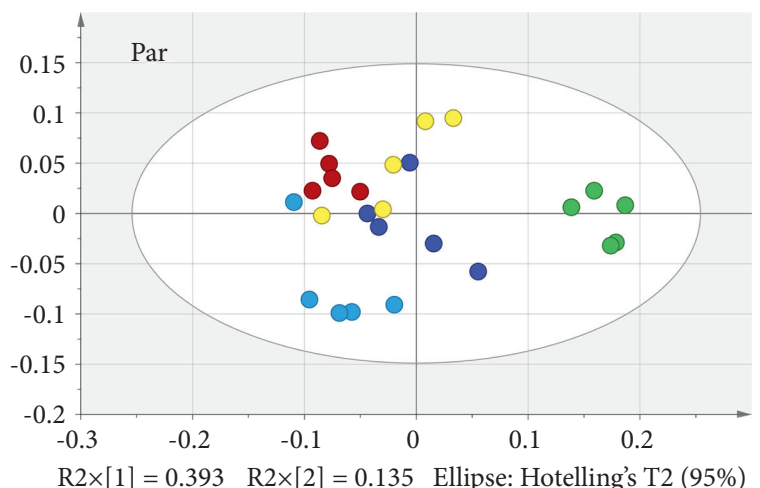

ya sf

(c)

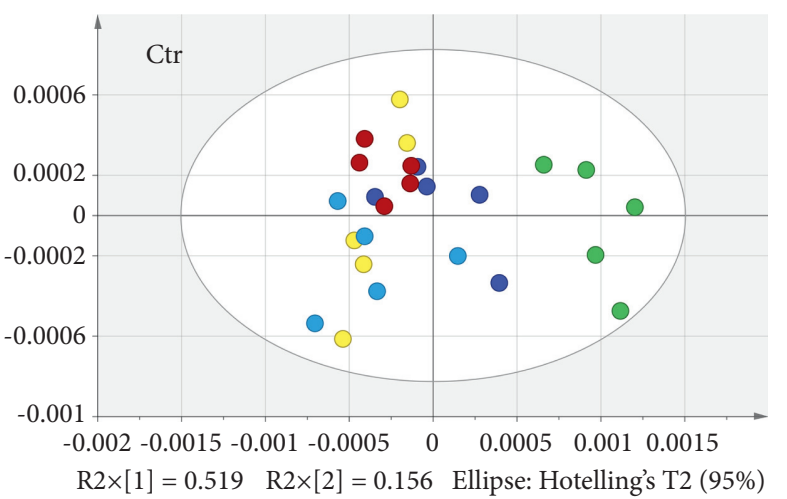

ya
ga
wa sf

(e)

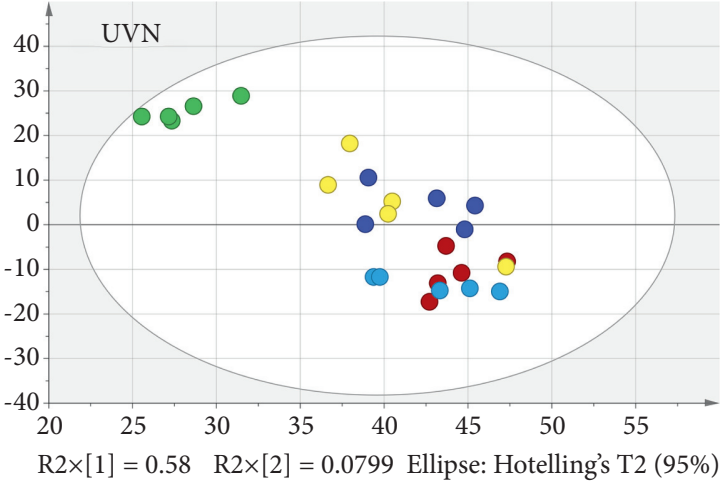

sf

(b)

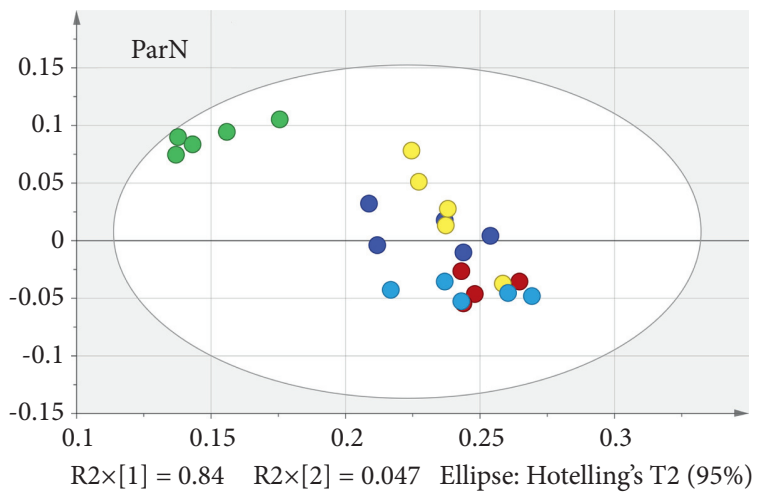

ya

sf

(d)

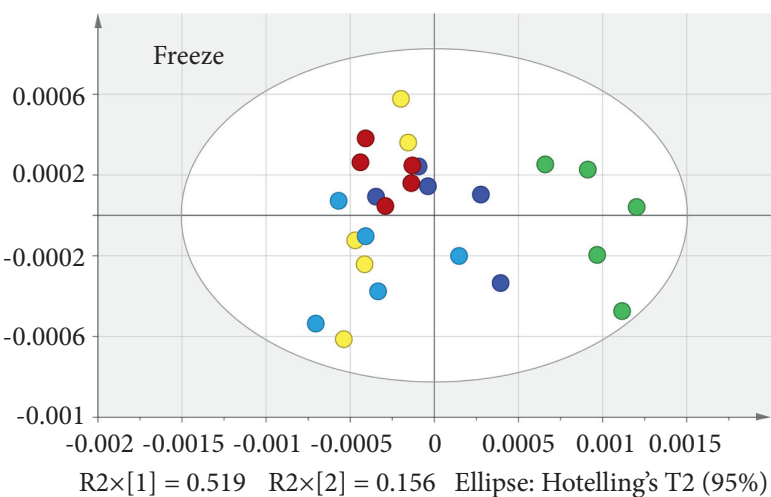
ya
ga
wa
sf

FIgURE 3: PCA scatter plot of six scaling methods. 


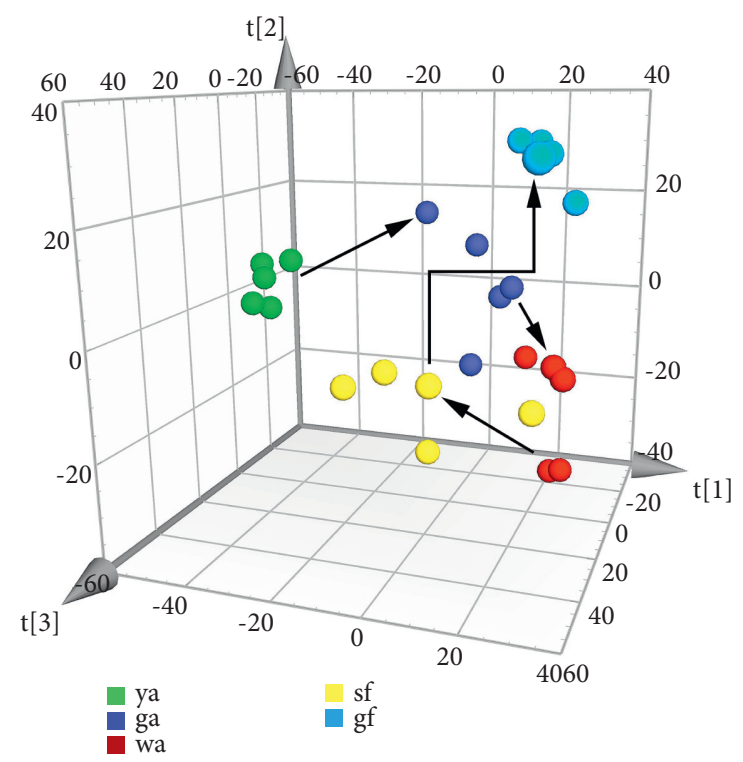

FIgURE 4: PCA scatter plot with UV scaling.

between the two adjacent harvesting periods and their differential chemical compositions, the OPLS-DA was performed in this study [36]. The OPLS-DA scatter plot from the ya stage to the ga stage is shown in Figure 5(a). The model fitting parameter $R^{2} Y=l$, and the model prediction parameter $Q^{2}=0.96$, indicating that the model had a good fitting degree and strong predictive ability. It can be observed that the ya stage and the ga stage could be well distinguished, indicating that there were significant differences between the samples in these two periods. In the permutation test plot (Figure 5(b)), $R^{2}=0.999, Q^{2}=-0.0406$, and all the points on the left of $R^{2}$ and $Q^{2}$ were lower than the rightmost point. It was concluded that the data were not overfitting, and the model could be used for the screening of differential markers. The contribution values greater than 0.8 in the S-line plot (Figure 6(a)) were $2987 \mathrm{~cm}^{-1}, 2948 \mathrm{~cm}^{-1}$, $2900 \mathrm{~cm}^{-1}, 1400 \mathrm{~cm}^{-1}, 1254 \mathrm{~cm}^{-1}, 1094 \mathrm{~cm}^{-1}, 1078 \mathrm{~cm}^{-1}$, and $1051 \mathrm{~cm}^{-1}$. According to Table 1, it could be concluded that the main components that caused the change from the ya stage to the ga stage might be flavonoids or phenolic acid compounds, and nutrients, such as lipids, sugars, nucleic acids, and proteins. Research by Cui et al. [37] showed that the flavonoid content increased first and then decreased during the growth and development process of Lonicera japonica using the HPLC method. The increase in flavonoid content was probably caused by the increased activity of the chalcone isomerase, which catalyzes its synthesis [38]. Moreover, Zhang et al. [39] found that the content of phenolic acid compounds increased during the period from the ya stage to the ga stage. These research results were consistent with this study.

The OPLS-DA scatter plot from the ga stage to the wa stage is shown in Figure 5(c). The model fitting parameter $R^{2} Y=1$, and the model prediction parameter $Q^{2}=0.871$, indicating that there was a good fitting degree and predictability. In the permutation test plot (Figure 5(d)), $R^{2}=0.988$ and $Q^{2}=-0.0889$, and when the proportion of the displacing $Y$ variable increases, the $Q^{2}$ of the stochastic model gradually decreases, indicating that the data were not overfitting. According to the S-line plot (Figure 6(b)) based on the rule of the contribution values greater than 0.8 , $3025 \mathrm{~cm}^{-1}, 2979 \mathrm{~cm}^{-1}, 2947 \mathrm{~cm}^{-1}, 1710 \mathrm{~cm}^{-1}, 1688 \mathrm{~cm}^{-1}$, and $1561 \mathrm{~cm}^{-1}, 1388 \mathrm{~cm}^{-1}, 1021 \mathrm{~cm}^{-1}$, and $806 \mathrm{~cm}^{-1}$ were confirmed. Accordingly, it could be concluded that the main components causing the change from the ga stage to the wa stage were similar to the result from the ya stage to the ga stage. However, among them, $1710 \mathrm{~cm}^{-1}, 1688 \mathrm{~cm}^{-1}$, $1388 \mathrm{~cm}^{-1}$, and $806 \mathrm{~cm}^{-1}$ were the characteristic absorption of caffeoylquinic acid, chlorogenic acid, and flavonoids, which showed more chemical information of phenolic acids and flavonoids than other periods. Furthermore, the phenolic acids and flavonoids showed the most substantial infrared absorption peaks in the wa stage, indicating that the content of phenolic acids and flavonoids (the quality control index of Lonicera japonica) is at the highest level [40]. Meanwhile, Wang et al. [41] studied the content changes in the main active constituents of Lonicera japonica at different stages. The results showed that with the development of flower buds, the content of phenolic acids increased firstly, then decreased, and reached the peak value at the wa stage. Kong et al. [38] discovered that the content of flavonoids increased firstly and then decreased during the growth and development periods of Lonicera japonica. The highest content was also found at the wa stage. From the above study, phenolic acids and flavonoids were the differential components that caused the changes in the ga and wa stages, which were in line with the results of previous researchers.

The OPLS-DA scatter plot from the wa stage to the sf stage is shown in Figure 5(e). The model fitting parameter $R^{2} Y=1$, and the model prediction parameter $Q^{2}=0.919$, indicating an excellent model fit and high predictability. In the permutation test plot (Figure 5(f)), $R^{2}=0.997$ and $Q^{2}=-0.0278$, indicating that the model could be used for the screening of differential markers. The contribution values greater than 0.8 in the S-line plot (Figure 6(c)) were $2987 \mathrm{~cm}^{-1}, 2873 \mathrm{~cm}^{-1}, 1650 \mathrm{~cm}^{-1}, 1376 \mathrm{~cm}^{-1}, 1060 \mathrm{~cm}^{-1}$, and $1039 \mathrm{~cm}^{-1}$. It could be concluded that the main components causing the change from the wa stage to the sf stage might be iridoids, phenolic acids or flavonoids, and nutrients, such as lipids, sugars, nucleic acids, and proteins. Wang et al. [42] found that with the development of Lonicera japonica flower buds, the iridoids showed a trend, which decreased first, then increased, and finally dropped, with the highest content appearing at the wa stage and the sf stage. Fu et al. [8] observed that phenolic acid content was significantly reduced as the flowers opened. Therefore, phenolic acid content showed a downward trend from the wa stage to the sf stage. Cui et al. [37] revealed that the flavonoid content tends to decrease during the period from the wa stage to the sf stage. This might be attributed to the competition of chalcone isomerase for precursors at the sf stage [38]. Therefore, these results in this study were in agreement with previous reports.

Finally, the OPLS-DA scatter plot from the sf stage to the gf stage is shown in Figure 5(g). Similar to the aboveestablished model, this model also showed a good fitting 


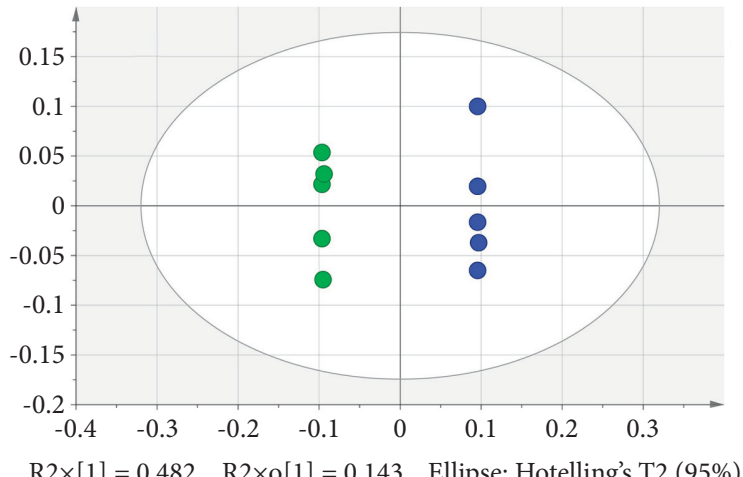

$\mathrm{R} 2 \times[1]=0.482 \mathrm{R} 2 \times \mathrm{o}[1]=0.143 \quad$ Ellipse: Hotelling's T2 (95\%)

$$
\begin{aligned}
& \text { ya } \\
& \text { ga }
\end{aligned}
$$

(a)

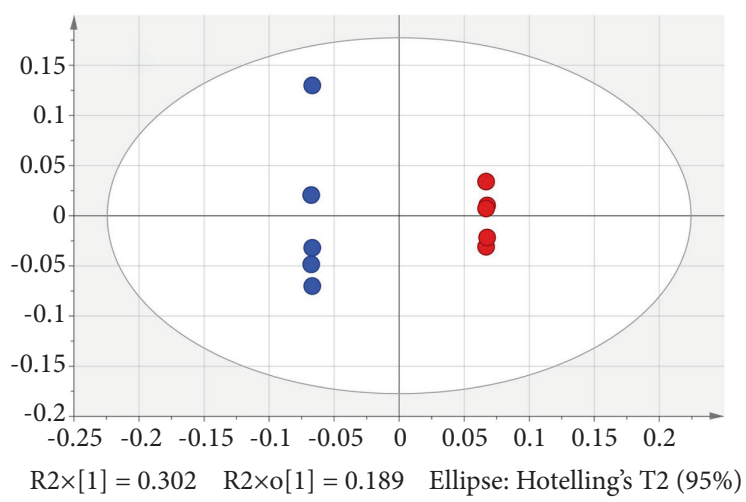

ga

(c)

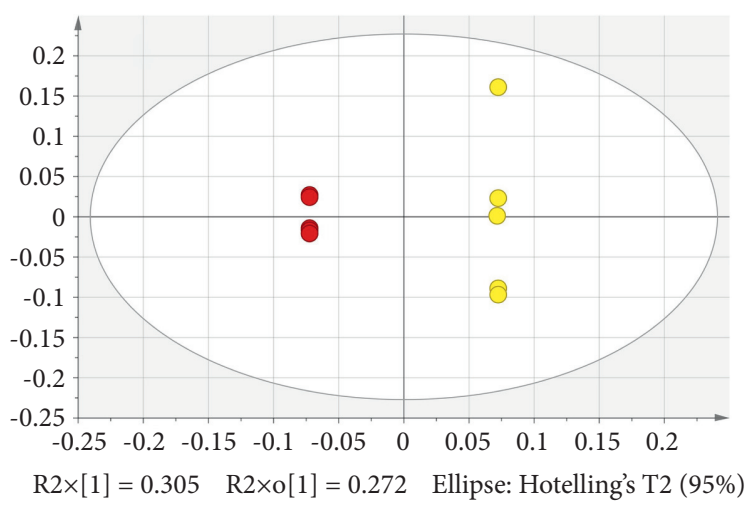

$\mathrm{R} 2 \times[1]=0.305 \quad \mathrm{R} 2 \times \mathrm{o}[1]=0.272 \quad$ Ellipse: Hotelling's T2 (95\%)

wa
sf

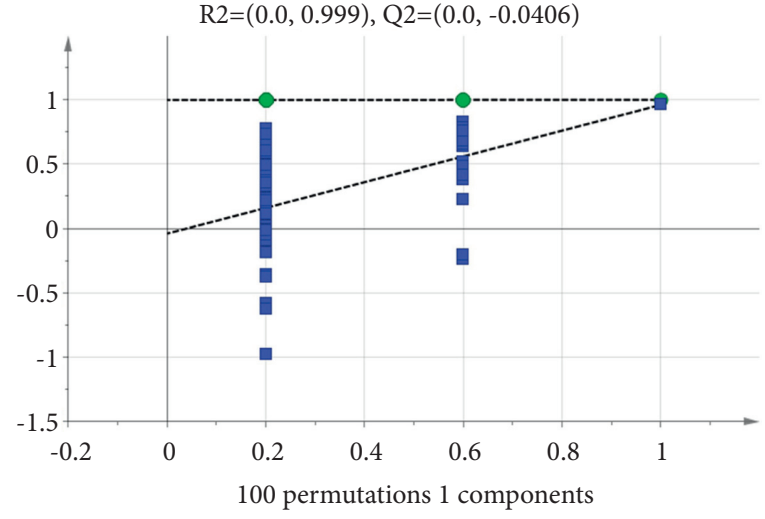

- $\mathrm{R} 2$

(b)

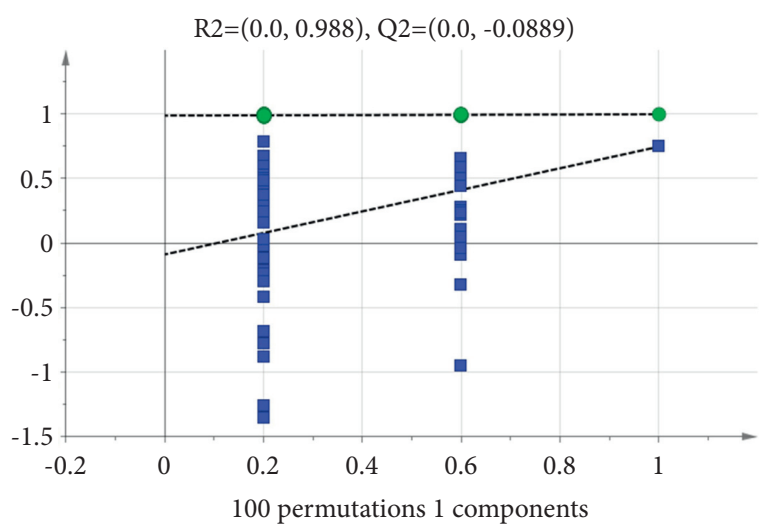

- R2

(d)

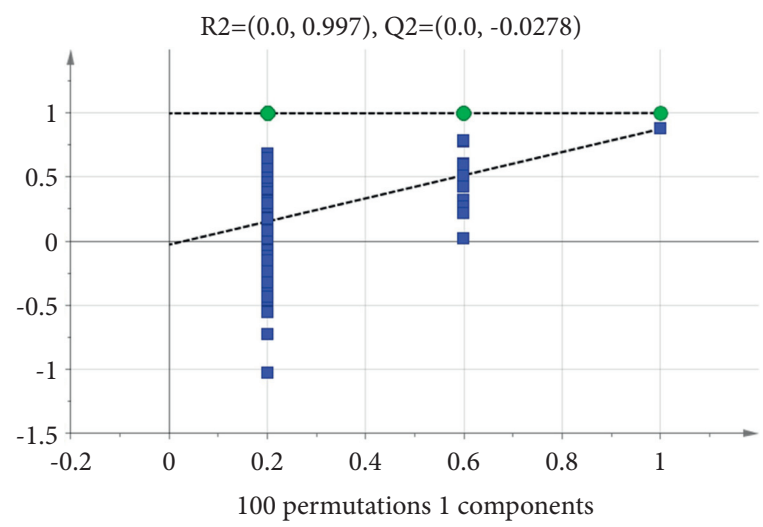

- R2

- Q2

(e)

(f)

Figure 5: Continued. 


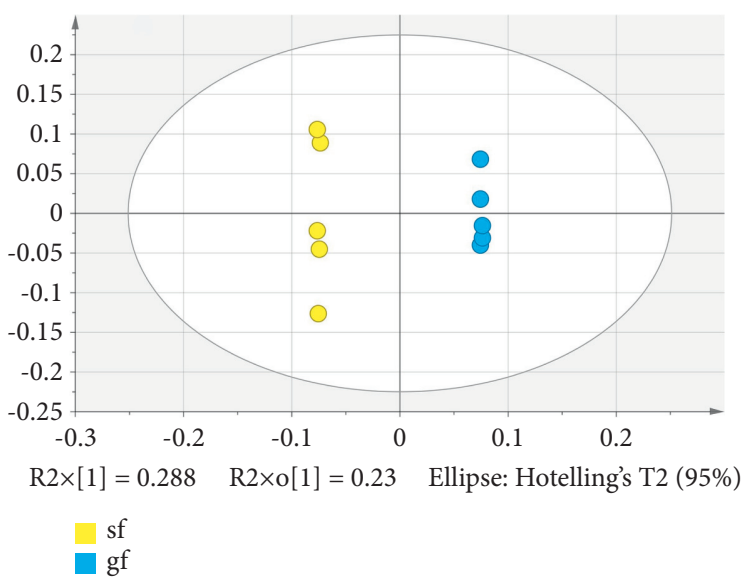

$(\mathrm{g})$

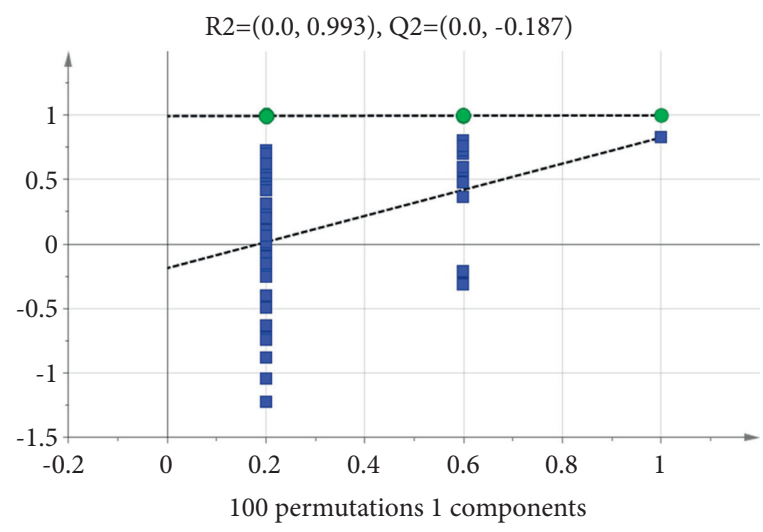

- $\mathrm{R} 2$

(h)

FigURE 5: Scatter plot and permutation test plot of OPLS-DA models.

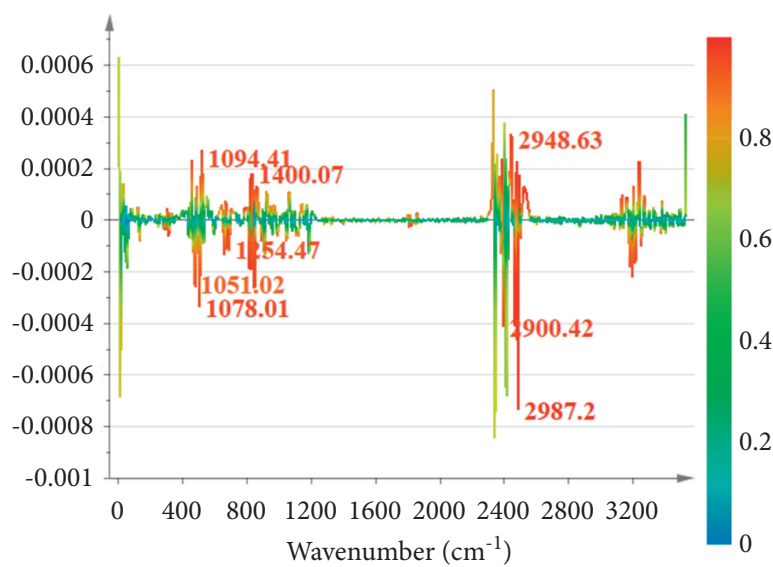

(a)

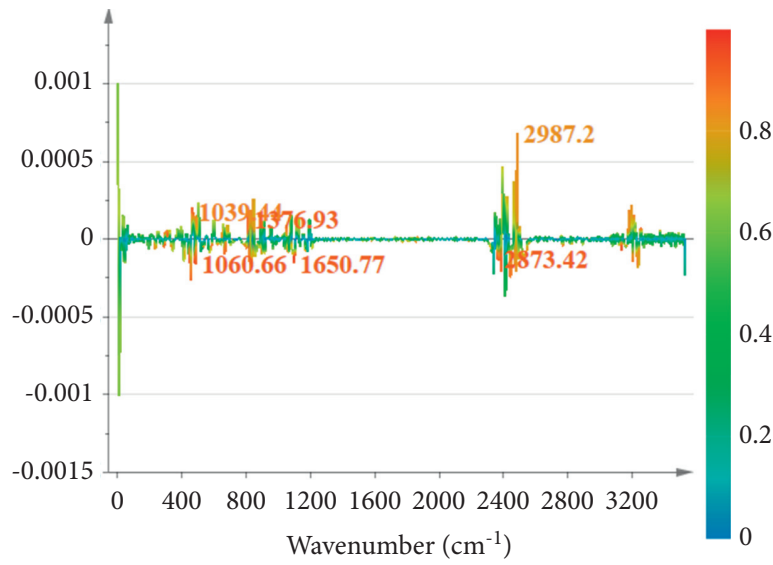

(c)

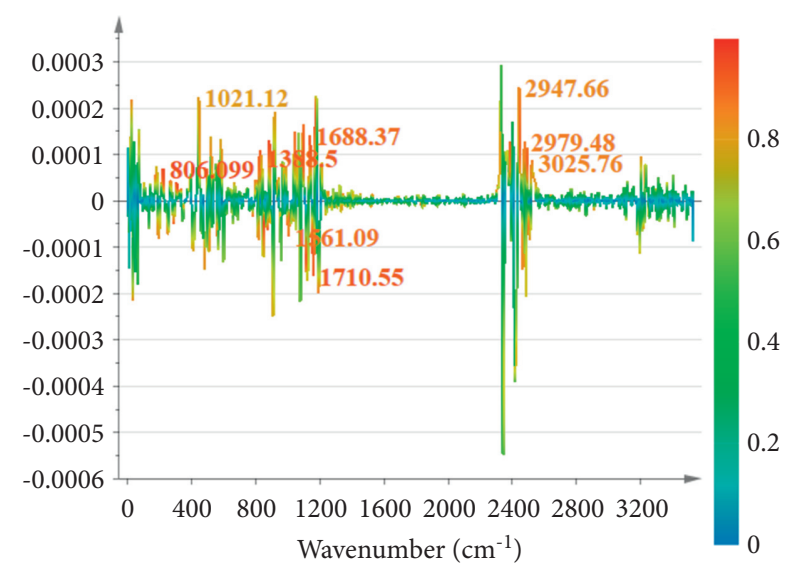

(b)

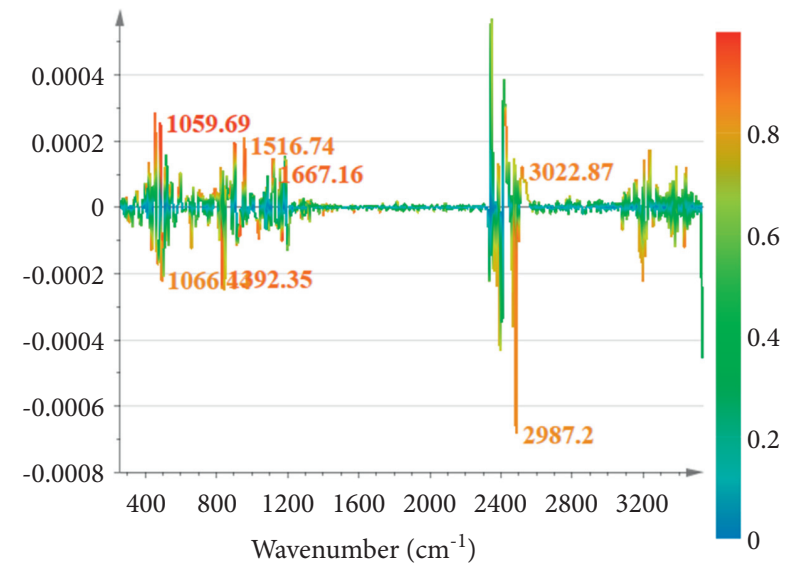

(d)

FIgURE 6: S-line plot of OPLS-DA models.

degree and strong predictive ability $\left(R^{2} Y=0.999, Q^{2}=0.827\right)$ and the permutation test plot (Figure $5(\mathrm{~h})$ ) showed nonsignificant overfitting $\left(R^{2}=0.993, Q^{2}=-0.187\right)$. According to the S-line plot (Figure 6(d)), the contribution values of $3022 \mathrm{~cm}^{-1}, 2987 \mathrm{~cm}^{-1}, 1667 \mathrm{~cm}^{-1}, 1516 \mathrm{~cm}^{-1}, 1392 \mathrm{~cm}^{-1}$, $1066 \mathrm{~cm}^{-1}$, and $1059 \mathrm{~cm}^{-1}$ were all greater than 0.8 . This 
showed that the main components that caused the change from the sf stage to the gf stage might be volatile oils, phenolic acids or flavonoids, and nutrients, such as lipids, sugars, nucleic acids, and proteins. Wang et al. [41] showed that the content of volatile oil compounds increases in the flower bud stage, peaks in the sf stage, and then decreased. The change in volatile oil content showed certain flowering time dependence, indicating that some chemical components might accumulate during a particular period as the plant adapts to changes in its environment [43, 44]. Kong et al. [38] discovered that after the flowering of Lonicera japonica, the content of phenolic compounds significantly reduces till the gf stage when the content is minimal. The reduction in chlorogenic acid content might result from the increased biosynthesis of lignin using chlorogenic acid as a substrate during the gf stage. Zhang et al. [39] showed that the content of flavonoids decreases during the period from the sf stage to the gf stage of Lonicera japonica. These previous reports indicated that volatile oils, phenolic acids, and flavonoids were the differential components that cause changes in the sf and gf stages, which were in accordance with the results of this study.

In summary, ATR-FTIR combined with chemometrics was used to establish chemical information fingerprint and classification and discrimination model of Lonicera japonica in different harvesting periods. It showed that this method could scientifically evaluate the variation of active components among different harvesting periods of Lonicera japonica. Moreover, ATR-FTIR technology is simple, rapid, effective, and applicable to Chinese medicine. However, in the determination of the infrared spectrum, there exist some spectral absorptions of the interfering components and the absorption peak probably generates superposition phenomenon, which has a certain impact on the accuracy of the determination results. Therefore, the determination of the differential components of Lonicera japonica at different harvesting periods still needs to be further studied in conjunction with other analytical techniques.

\section{Data Availability}

All related data are included within the article.

\section{Conflicts of Interest}

The authors declare that there are no conflicts of interest.

\section{Authors' Contributions}

Yun-Chu Zhang and Jing Deng contributed equally.

\section{Acknowledgments}

This study was supported by the National Key R\&D Program of China (2017YFC1701900), the Natural Science Foundation of Hunan Province (2017JJ4045), and the ResearchBased Learning and Innovative Experiment Program for College Students of Hunan Province (1021-0001017174).

\section{References}

[1] M.-Q. Shan, T.-J. Wang, Y.-L. Jiang et al., "Comparative analysis of sixteen active compounds and antioxidant and anti-influenza properties of Gardenia jasminoides fruits at different times and application to the determination of the appropriate harvest period with hierarchical cluster analysis," Journal of Ethnopharmacology, vol. 233, pp. 169-178, 2019.

[2] S. Poyraz EngIN and C. Mert, "The effects of harvesting time on the physicochemical components of aronia berry," Turkish Journal of Agriculture and Forestry, vol. 44, no. 4, pp. 361-370, 2020.

[3] M. Rutkowska, E. Balcerczak, R. Świechowski, M. Dubicka, and M. A. Olszewska, "Seasonal variation in phenylpropanoid biosynthesis and in vitro antioxidant activity of Sorbus domestica leaves: harvesting time optimisation for medicinal application," Industrial Crops and Products, vol. 156, Article ID 112858, 2020.

[4] C. Zeng, H. Lin, Z. Liu, and Z. Liu, "Metabolomics analysis of Camellia sinensis with respect to harvesting time," Food Research International, vol. 128, Article ID 108814, 2020.

[5] Commission CP, Pharmacopoeia of the People's Republic of China, China Medical Science Press, Beijing, China, 2015.

[6] X. Y. Chai, S. L. Li, and P. Li, "Quality evaluation of Flos Lonicerae through a simultaneous determination of six saponins by HPLC with ELSD," Journal of Chromatography, A, vol. 1070, no. 1-2, pp. 43-48, 2005.

[7] M. Jiang, Y.-Q. Han, M.-G. Zhou et al., “The screening research of anti-inflammatory bioactive markers from different flowering phases of Flos Lonicerae Japonicae," PLoS One, vol. 9, no. 5, Article ID e96214, 2014.

[8] M. Fu, Q. Qu, and H. Dai, "Variation in antioxidant properties and metabolites during flower maturation of Flos Lonicerae Japonicae flowers," European Food Research and Technology, vol. 240, no. 4, pp. 735-741, 2015.

[9] N. Cebi, M. T. Yilmaz, and O. Sagdic, "A rapid ATR-FTIR spectroscopic method for detection of sibutramine adulteration in tea and coffee based on hierarchical cluster and principal component analyses," Food Chemistry, vol. 229, pp. 517-526, 2017.

[10] L. Suárez, R. García, F. A. Riera, and M. A. Diez, “ATR-FTIR spectroscopy for the determination of Na4EDTA in detergent aqueous solutions," Talanta, vol. 115, pp. 652-656, 2013.

[11] R. Karoui, G. Downey, and C. Blecker, "Mid-infrared spectroscopy coupled with chemometrics: a tool for the analysis of intact food systems and the exploration of their molecular structure-quality relationships-a review," Chemical Reviews, vol. 110, no. 10, pp. 6144-6168, 2010.

[12] N. Arroyo-Manzanares, B. Markiv, J. D. Hernández et al., "Head-space gas chromatography coupled to mass spectrometry for the assessment of the contamination of mayonnaise by yeasts," Food Chemistry, vol. 289, pp. 461-467, 2019.

[13] Y. Li, S. Fan, A. Li et al., "Vintage analysis of Chinese Baijiu by GC and 1H NMR combined with multivariable analysis," Food Chemistry, vol. 360, no. 5, Article ID 129937, 2021.

[14] Y. Liu, Y. Wang, Z. Xia, Y. Wang, Y. Wu, and Z. Gong, "Rapid determination of phytosterols by NIRS and chemometric methods," Spectrochimica Acta Part A: Molecular and Biomolecular Spectroscopy, vol. 211, pp. 336-341, 2019.

[15] B.-J. Lee, H.-Y. Kim, S. R. Lim, L. Huang, and H.-K. Choi, "Discrimination and prediction of cultivation age and parts of Panax ginseng by Fourier-transform infrared spectroscopy combined with multivariate statistical analysis," PLoS One, vol. 12, no. 10, Article ID e0186664, 2017. 
[16] B.-J. Lee, Y. Zhou, J. S. Lee et al., "Discrimination and prediction of the origin of Chinese and Korean soybeans using Fourier transform infrared spectrometry (FT-IR) with multivariate statistical analysis," PLoS One, vol. 13, no. 4, Article ID e0196315, 2018.

[17] S. Wiklund, E. Johansson, L. Sjöström et al., "Visualization of GC/ TOF-MS-based metabolomics data for identification of biochemically interesting compounds using OPLS class models," Analytical Chemistry, vol. 80, no. 1, pp. 115-122, 2008.

[18] A. M. Adib, F. Jamaludin, L. S. Kiong, N. Hashim, and Z. Abdullah, "Two-dimensional correlation infrared spectroscopy applied to analyzing and identifying the extracts of Baeckea frutescens medicinal materials," Journal of Pharmaceutical and Biomedical Analysis, vol. 96, pp. 104-110, 2014.

[19] S. Olsztyńska-Janus, A. Pietruszka, Z. Kiełbowicz, and M. A. Czarnecki, "ATR-IR study of skin components: lipids, proteins and water. Part I: temperature effect," Spectrochimica Acta, Part A: Molecular and Biomolecular Spectroscopy, vol. 188, pp. 37-49, 2018.

[20] X. Zhou, Q. Dong, X. Kan et al., "Immunomodulatory activity of a novel polysaccharide from Lonicera japonica in immunosuppressed mice induced by cyclophosphamide," PLoS One, vol. 13, no. 10, Article ID e0204152, 2018.

[21] R. Yan, J.-B. Chen, S.-Q. Sun, and B.-L. Guo, "Rapid identification of Lonicerae japonicae Flos and Lonicerae Flos by Fourier transform infrared (FT-IR) spectroscopy and twodimensional correlation analysis," Journal of Molecular Structure, vol. 1124, pp. 110-116, 2016.

[22] Y. Li, D. Kong, and H. Wu, "Comprehensive chemical analysis of the flower buds of five Lonicera species by ATR-FTIR, HPLC-DAD, and chemometric methods," Revista Brasileira de Farmacognosia, vol. 28, no. 5, pp. 533-541, 2018.

[23] A. Inan Genç, S. Gok, S. Banerjee, and F. Severcan, "Valdecoxib recovers the lipid composition, order and dynamics in colon cancer cell lines independent of COX-2 expression: an ATR-FTIR spectroscopy study," Applied Spectroscopy, vol. 71, no. 1, pp. 105-117, 2017.

[24] M. Pucetaite, M. Velicka, V. Urboniene et al., "Rapid intraoperative diagnosis of kidney cancer by attenuated total reflection infrared spectroscopy of tissue smears," Journal of Biophotonics, vol. 11, no. 5, Article ID e201700260, 2018.

[25] F. Bonnier, G. Brachet, R. Duong et al., "Screening the low molecular weight fraction of human serum using ATR-IR spectroscopy," Journal of Biophotonics, vol. 9, no. 10, pp. 1085-1097, 2016.

[26] Y. Otsuka, M. Takeuchi, M. Otsuka, B. Ben-Nissan, D. Grossin, and H. Tanaka, "Effect of carbon dioxide on selfsetting apatite cement formation from tetracalcium phosphate and dicalcium phosphate dihydrate; ATR-IR and chemoinformatics analysis," Colloid \& Polymer Science, vol. 293, no. 10, pp. 2781-2788, 2015.

[27] R. Nikzad-Langerodi, S. Ortmann, E. M. Pferschy-Wenzig et al., "Assessment of anti-inflammatory properties of extracts from Honeysuckle (Lonicera sp. L., Caprifoliaceae) by ATRFTIR spectroscopy,” Talanta, vol. 175, pp. 264-272, 2017.

[28] S. Wu, Y. Jin, Q. Liu et al., "On-line quantitative monitoring of liquid-liquid extraction of Lonicera japonica and Artemisia annua using near-infrared spectroscopy and chemometrics," Pharmacognosy Magazine, vol. 11, no. 43, pp. 643-50, 2015.

[29] Z. Wu, C. Sui, B. Xu et al., "Multivariate detection limits of online NIR model for extraction process of chlorogenic acid from Lonicera japonica," Journal of Pharmaceutical and Biomedical Analysis, vol. 77, pp. 16-20, 2013.
[30] E. Staniszewska-Slezak, L. Mateuszuk, S. Chlopicki, M. Baranska, and K. Malek, "Alterations in plasma biochemical composition in NO deficiency induced by L-NAME in mice analysed by Fourier Transform Infrared Spectroscopy," Journal of Biophotonics, vol. 9, no. 10, pp. 1098-1108, 2016.

[31] Y. Yang, L. Wang, Y. Wu et al., "On-line monitoring of extraction process of Flos Lonicerae Japonicae using near infrared spectroscopy combined with synergy interval PLS and genetic algorithm," Spectrochimica Acta Part A: Molecular and Biomolecular Spectroscopy, vol. 182, pp. 73-80, 2017.

[32] Z. He, C. Qiao, Q. Han, Y. Wang, W. Ye, and H. Xu, "New triterpenoid saponins from the roots of Platycodon grandiflorum," Tetrahedron, vol. 61, no. 8, pp. 2211-2215, 2005.

[33] X. Xiao, J. Ma, F. Ge et al., "Application of near-infrared spectroscopy for the rapid analysis ofLonicerae Japonicae Flossolution extracted by water," Journal of Innovative Optical Health Sciences, vol. 7, no. 4, Article ID 1350063, 2014.

[34] C. Mees, F. Souard, C. Delporte et al., "Identification of coffee leaves using FT-NIR spectroscopy and SIMCA," Talanta, vol. 177, pp. 4-11, 2018.

[35] M. Ringnér, "What is principal component analysis?" Nature Biotechnology, vol. 26, no. 3, p. 303, 2008.

[36] J. Boccard and D. N. Rutledge, "A consensus orthogonal partial least squares discriminant analysis (OPLS-DA) strategy for multiblock Omics data fusion," Analytica Chimica Acta, vol. 769, pp. 30-39, 2013.

[37] X. S. Cui, M. Zhao, Q. C. Tian, X. Q. Gao, F. Qi, and Y. H. Guo, "The relationship between floral organ development period and effective component content of Lonicera japonica," Chinese Agricultural Science Bulletin, vol. 34, no. 4, pp. 71-75, 2018.

[38] D.-X. Kong, Y.-Q. Li, M. Bai, H.-J. He, G.-X. Liang, and $\mathrm{H}$. $\mathrm{Wu}$, "Correlation between the dynamic accumulation of the main effective components and their associated regulatory enzyme activities at different growth stages in Lonicera japonica Thunb," Industrial Crops and Products, vol. 96, pp. 16-22, 2017.

[39] Y. Zhang, W. Wang, L. Guo et al., "Study on yield and quality of Lonicerea Japonicae Flos in different harvest seasons," Chinese Herbal Medicines, vol. 44, pp. 2611-2614, 2013.

[40] Y. Yuan, L. Song, M. Li et al., "Genetic variation and metabolic pathway intricacy govern the active compound content and quality of the Chinese medicinal plant Lonicera japonica thunb," BMC Genomics, vol. 13, no. 1, p. 195, 2012.

[41] L.-M. Wang, M.-T. Li, Y.-Y. Yan, M.-Z. Ao, G. Wu, and L.-J. Yu, "Influence of flowering stage of Lonicera japonicaThunb. on variation in volatiles and chlorogenic acid," Journal of the Science of Food and Agriculture, vol. 89, no. 6, pp. 953-957, 2009.

[42] L. N. Wang, X. F. Sun, F. Zhang, and Y. Q. Zhang, "Research on correlation between color and active compounds of Lonicerae Japonicae Flos in different development periods," Chinese Traditional and Herbal Drugs, vol. 48, no. 15, p. 3182, 2017.

[43] E. V. Koenen, Medicinal, Poisonous, and Edible Plants in Namibia, Klaus Hess Publishers, Hohenhorn, Germany, 2001.

[44] G. P. P. Kamatou, R. L. Van Zyl, S. F. Van Vuuren et al., "Seasonal variation in essential oil composition, oil toxicity and the biological activity of solvent extracts of three South African Salvia species," South African Journal of Botany, vol. 74, no. 2, pp. 230-237, 2008. 